\title{
Parent-absent begging in the Brown-headed Cowbird (Molothrus ater): the role of short-term need and nestmate size
}

\author{
James W. Rivers
}

Received: 13 March 2008 /Revised: 16 December 2008 /Accepted: 17 December 2008 / Published online: 14 January 2009

(C) The Author(s) 2009. This article is published with open access at Springerlink.com

\begin{abstract}
Although it is well-established that nestlings of many altricial species beg when parents are away from the nest, we have a poor understanding of parent-absent begging in brood parasites, including the proximate factors that may influence begging frequency and intensity. In this study, I examined how parent-absent begging was influenced by competitive asymmetries between host and Brown-headed Cowbird (Molothrus ater) nestlings under disparate levels of short-term need. Food-deprived cowbird nestlings begged more frequently and for a greater proportion of parent-absent period than when food-supplemented, with similar patterns observed in hosts of different sizes. In contrast, three metrics of cowbird begging intensity varied relative to host size but not due to differences in short-term need. Cowbirds consistently begged more frequently and intensively than host nestlings for a given level of short-term need, providing evidence that cowbird begging displays are more frequent and intense than non-parasitic nestlings during both feeding visits and parent-absent periods. In sum, the frequency of begging by cowbirds was only influenced by short-term need, whereas begging intensity during parent-absent events was only influenced by the host against which cowbirds competed. This study demonstrates that host size and shortterm need had differing influences on the frequency and intensity of parent-absent begging in cowbirds, although both factors are likely important in limiting the evolution of parent-absent begging in cowbirds. Because it appears to provide no immediate benefits yet may decrease fitness,
\end{abstract}

Communicated by M. Soler.

J. W. Rivers $(\triangle)$

Department of Ecology, Evolution, and Marine Biology,

University of California-Santa Barbara,

Santa Barbara, CA 93106-9610, USA

e-mail: rivers@lifesci.ucsb.edu parent-absent begging should be included in future theoretical models investigating the evolution of begging displays in nestling birds.

Keywords Parent-absent begging - Molothrus ater . Brown-headed Cowbird · Generalist brood parasite · Begging

\section{Introduction}

Among altricial birds, nestlings use a combination of vocalizations and physical movements to elicit feeding by parents (hereafter begging; Kilner and Johnstone 1997; Budden and Wright 2001a). Many researchers have noted that begging behavior is common during parental absences (hereafter, parent-absent begging), and a number of recent investigations have been undertaken to offer explanations for its occurrence and document the factors that influence parent-absent begging (Roulin et al. 2000; Budden and Wright 2001b; Leonard and Horn 2001; Maurer et al. 2003; Dickens and Hartley 2007; Dor et al. 2007; Bulmer et al. 2008). Several explanations have been formed to explain the occurrence of parent-absent begging as either signaling among relatives or a response to inappropriate stimuli (reviewed in Dor et al. 2007). The sibling negotiation hypothesis posits that parent-absent begging is a way by which nestlings signal to nestmates their willingness to compete for food resources during a subsequent feeding visit (Roulin et al. 2000). Supporting evidence for this hypothesis largely comes from studies of nestling barn owls (Tyto alba, but see Bulmer et al. 2008) that have found that nestlings that call most frequently during parent-absent intervals are more likely to be provisioned when parents return to the nest with food (Roulin et al. 2000; Roulin 2002). The second hypothesis, parental communication, 
argues that nestlings signal to parents who are away from the nest, thereby minimizing the number of trips parents make and drawing as little attention to the nest as possible (Maurer et al. 2003). Although at least two studies have suggested that nestlings signal to parents away from the nest (Price and Ydenberg 1995; Maurer et al. 2003), direct tests of this idea are lacking, and the extent to which it explains parent-absent begging is presently unknown. An additional, proximate explanation for parent-absent begging, the inappropriate stimulus hypothesis, is based on the observation that nestlings often initiate begging to incorrect apparent stimuli in the vicinity of the nest (e.g., the movement of the nest due to wind action) during the early part of the nestling period. However, as the sensory modalities of nestlings improve with age, the frequency of parent-absent begging declines (Clemmons 1995; Budden and Wright 2001b; Dor et al. 2007) indicating that the extent of parent-absent begging varies with nestling developmental stage. The development and testing of these hypotheses have clearly expanded our understanding of why parent-absent begging may occur; yet, we still lack a firm understanding of how proximate-level factors within nests influence parent-absent begging behavior. This is important because some proximate factors that influence early nest environments, such as competitive asymmetries within the brood, may have strong effects on offspring fitness (e.g., Forbes and Glassey 2000).

Generalist brood parasites provide a model group for examining how nestmate size influences nestling begging behavior because they are often raised by hosts that differ with respect to their size (e.g., Friedmann and Kiff 1985; Davies 2000). Moreover, because brood parasites are unrelated to host parents and, under most circumstances, compete against unrelated siblings (Rothstein 1990; Davies 2000), they provide a group that are predicted to respond differently than nonparasitic species to short-term need and beg more intensively than nonparasitic species for a given level of hunger (Harper 1986; Motro 1989; Holen et al. 2001). Although much work has gone into studying the begging of brood parasites during feeding visits by parents (e.g., Lichtenstein and Sealy 1998; Kilner et al. 1999) and in laboratory settings without attendant parents (e.g., Redondo 1993; Lichtenstein 2001; Hauber 2003), no studies have yet quantified how proximate factors influence parent-absent begging in brood parasites under natural conditions.

Here, I examine parent-absent begging in the broodparasitic Brown-headed Cowbird (Molothrus ater; hereafter cowbird) using data collected during the course of a related experiment that examined the influence of proximate factors on cowbird begging behavior during feeding visits (Rivers 2007). In broods comprising two chicks (one cowbird, one host), I tested two general hypotheses regarding the parent- absent begging of cowbirds, namely that begging frequency and intensity increases with nestmate size and hunger level. With respect to host nestmate size, parent-absent begging by cowbirds is predicted to be more frequent and intense with an increase in nestmate size, as large nestlings are typically able to dominate smaller nestmates during provisioning events (e.g., Teather 1992; Price and Ydenberg 1995). With respect to short-term need, food-deprived cowbird nestlings are predicted to beg more frequently and intensively when supplemented with food because food deprivation typically increases begging activity (Budden and Wright 2001a). Finally, I also tested the hypothesis that the frequency and intensity of parent-absent begging of cowbirds was greater than host nestlings for a given level of need because the begging behavior of brood parasites is viewed as being unrestrained by inclusive fitness costs (Harper 1986; Motro 1989; Holen et al. 2001).

\section{Materials and methods}

\section{Study area and host species}

Parent-absent begging of cowbird and host nestlings was examined during the 2002-2003 breeding seasons at Konza Prairie Biological Station $\left(39^{\circ} 05^{\prime} \mathrm{N}, 96^{\circ} 35^{\prime} \mathrm{W}\right)$, a 3,487-ha tallgrass prairie research area located in northeastern Kansas, USA. Cowbirds are an abundant breeding species in this area and parasitize at least 24 host species on Konza Prairie (Elliot 1978; Parker 1999; Jensen and Cully 2005; J. W. Rivers et al., in review). Host nests used for this examination of parent-absent begging were also used in experiments that have been described in detail elsewhere (i.e., Rivers 2007). Briefly, before conducting experiments, I first categorized the Konza Prairie host community into three general classes: (1) hosts smaller than a cowbird for a given age, (2) hosts of similar size to a cowbird for a given age, and (3) hosts larger than a cowbird for a given age. As with previous studies that used nestling size as a proxy for competitive ability (e.g., Teather 1992; Price and Ydenberg 1995), I assumed that these categories would represent weak, moderate and strong nestling competitors, respectively, to a similar-aged cowbird nestling. During preliminary field work, I assessed which host species nested at densities high enough to provide adequate samples for experiments. Given these criteria, I was restricted to assessing cowbird begging in the nests of a single small host species (Field Sparrow [Spizella pusilla], hereafter sparrow), a single similar-sized host species (Redwinged Blackbird [Agelaius phoeniceus], hereafter blackbird), and a single large host species (Brown Thrasher [Toxostoma rufum], hereafter thrasher); additional details pertaining to host selection can be found in Rivers (2007). Nestlings of all three species are altricial, have similar 
patterns of growth as nestlings (Starck and Ricklefs 1998), and cover most of the size range of species against which cowbird nestlings typically compete (Friedmann and Kiff 1985; Lowther 1993). Although cowbird nestlings often hatch before host nestlings because of a short incubation period (Briskie and Sealy 1990), nestling age was standardized in experiments (see below) to control for developmental stage because differences of only 1-2 days in age can markedly influence the begging behaviors of nestlings and their ability to compete for food (Khayutin 1985). It should be noted that the thrasher typically rejects cowbird eggs placed in its nest (Rothstein 1975), although thrashers do occasionally raise cowbirds on the study site (J. W. Rivers, unpublished data). However, inclusion of the thrasher is warranted in this study because it was the only available large species that fulfilled the goal of isolating host size as a focal variable. Except for size and egg recognition, the thrasher is comparable to the two smaller hosts because all three species have similar nestling growth curves. Furthermore, there is no reason to believe that inclusion of a rejecter species along with two accepters is a confound because there is no evidence that nestling behaviors of any cowbird host, accepter or rejecter, have been shaped by cowbird parasitism.

\section{Field experiments}

Nestlings used in experiments were used only once during the course of the study and were tested at 3-5 days of age (where day 0 was the day of hatching) so that experiments were conducted during the peak of growth for both cowbird and host nestlings (Starck and Ricklefs 1998). At the time of experiments, the average mass of sparrow nestlings was $52 \%$ of the mass of the cowbirds against which they competed, the average mass of blackbird nestlings was $91 \%$ of the mass of the cowbirds against which they competed, and the average mass of thrasher nestlings was $175 \%$ of the mass of the cowbirds against which they competed (see "Results"). The average day-specific masses of nestling cowbirds used in this experiment were greater than predicted by the growth equation in Kilpatrick (2002) that was averaged over 19 hosts for which cowbird growth data are available (see Rivers 2007 for details). Therefore, the condition of cowbirds used in experiments was above average, and therefore, this factor likely is believed to have had a minimal influence on the patterns of begging observed in this study.

On the day before filming, broods of two nestlings (one cowbird and one host) of similar age ( \pm 1 day) were created by adding and/or removing nestlings. A single cowbird was added to most experimental nests (36 of 46) that initially lacked a cowbird, a single cowbird chick was removed from four nests that contained two cowbird nestlings, and the remaining six nests contained a single cowbird that was used in experimental trials. Most nests (40 of 46) contained more than one host nestling; in those cases, one host chick was randomly selected to remain in the nest for the experimental trial, while all other chicks were cross-fostered to available nests or removed under permit. The majority (i.e., $80 \%$ ) of nestling pairs that were filmed had hatched on the same day, and the remaining $20 \%$ of nestling pairs hatched within 1 day of each other. Logistical constraints made it impossible to control the nest environment of nestlings before experiments; however, nestlings had an average of $19 \mathrm{~h}$ (minimum, $11 \mathrm{~h}$ ) to acclimate to changes in their nest environment, which included $11 \mathrm{~h}$ of daylight during which parents could feed nestlings. This period was assumed to provide enough time for nestlings to adjust their behavior relative to their new environment, as at least one previous study found that nestlings changed their begging behavior relative to the size of their nestmates within $2 \mathrm{~h}$ of being placed in a new competitive environment (Price et al. 1996).

Although it was impossible to control the competitive environment experienced by cowbirds before experimental trials, cowbirds that were raised under the same initial conditions appeared to modify their begging behavior in response to the nest environment in which they were tested during the trials. By chance, each of three cowbird nestlings were raised alongside a single sparrow nestmate in three separate nests before experimental trials; each cowbird nestling was then tested in against one of the three hosts (i.e., small, similar-sized, and large) during an experimental trial. Also by chance, the same series of events took place for three additional cowbird nestlings, each of which was raised alongside three Dickcissel (Spiza americana) nestmates before experimental trials. In both cases, the begging behavior of the three cowbirds raised in the same initial host nest environment varied markedly from each other during trials and matched the overall pattern of begging of other cowbirds that competed against the same host (J. W. Rivers, unpublished data). These results indicate that the nest environment in which cowbirds were tested had a stronger influence on begging behavior than the nest environment they experienced before experimental trials and suggest that the early nest environment likely had minimal influence on cowbird begging behavior in this study.

At the time of brood creation, a plastic sham video camera was placed close to the nest to allow parents to acclimate to its presence. On the morning following the placement of the sham video camera, I returned to the nest and began filming nests between 06:00-08:00 CDT (except in one instance in which filming started at 08:30 due to equipment problems). Before filming, the mass of all nestlings was measured to the nearest $0.1 \mathrm{~g}$ with an electronic balance. After mass was taken, the sham video camera was replaced by a miniature video camera that was 
attached by $\sim 33 \mathrm{~m}$ of cable to a camcorder. The miniature video camera was capable of recording sound and had a field of view of approximately $2.2 \mathrm{~m}$ at $1 \mathrm{~m}$ from the camera. In nests containing similar-looking cowbird and blackbird nestlings, one randomly selected nestling was minimally marked on the bill with a non-toxic black felt marker to distinguish between nestlings on videotapes.

Two feeding treatments were applied to each nest in one of two sequences. Before both treatments, baseline begging and provisioning behaviors were videotaped for $90 \mathrm{~min}$ for purposes other than this study and are not considered further. In the first sequence, the recording of baseline data was followed by a supplementation treatment in which both nestlings were fed until satiation with commercially purchased mealworms, which were similar to food items typically fed to nestlings (J. W. Rivers, unpublished data). The feeding process generally took 1-2 min after which videotaping immediately commenced and lasted for $90 \mathrm{~min}$. After the supplementation treatment, a deprivation treatment was applied in which both nestlings were removed from the nest, held without food for $90 \mathrm{~min}$ and then returned to the nest. Immediately after their return, videotaping commenced and lasted for $90 \mathrm{~min}$. During deprivation treatments, focal nestlings were held in a sheltered, secure location, while one to three additional nestlings were swapped into the host nest to prevent abandonment. During cool weather, a hot water bottle was used to keep focal nestlings warm. The second sequence differed from the first sequence only in that the order of the deprivation and supplementation treatments were reversed. Each nest was randomly assigned to one of the two sequences, a similar number of each sequence was used for each host species, and no influence of sequence on begging behaviors was found during preliminary analyses.

\section{Quantification of parent-absent begging}

In a previous study (Rivers 2007), I quantified the begging behavior of cowbird and host nestlings in response to parents arriving at the nest with food. During that work, I examined begging during the 90 -min filming periods that followed each feeding treatment (Rivers 2007). Although the same sample of nests was used in this study, parentabsent begging behavior was only quantified in the first $30 \mathrm{~min}$ of videotapes (i.e., immediately after treatments were applied). This period was selected because visual examination of begging behavior data that occurred during parental feeding visits suggested that nestling begging behaviors that occurred in the initial 30 min after filming started were a reliable representation of begging behaviors over the entire 90-min period (Rivers, personal observation), and I assumed that parent-absent begging followed a similar pattern as begging during food provisioning events.
Parent-absent begging events were classified as those in which one or both nestlings begged (see below), yet parents were not observed at the immediate vicinity of the nest (i.e., they were outside the viewing field of the video camera, which was centered on the host nest). Although it is possible that nestlings begged in response to cues and/or signals that parents gave near the nest yet out of camera view, this appears to be unlikely for two reasons. First, altricial nestlings of the age as those tested in this study (i.e., 3-5 days post-hatch) have limited vision and appear to be unable to see beyond the nest cup (Khayutin 1985; A. B. Clark, personal communication). Thus, any visual stimuli given by parents near the nest were unlikely to be received by nestlings, and nestlings would only be able to respond to tactile or acoustic cues given by parents located away from the nest (Budden and Wright 2001b). Second, because parents of all three hosts typically approach the nest in a rapid, direct manner when feeding offspring and only give calls to elicit begging when perched at the edge of the nest cup (J.W. Rivers, unpublished data), any tactile or acoustic cues that parents may have given as they moved through vegetation when away from the nest cup were unlikely to be associated with provisioning. Therefore, begging events were classified as parent-absent begging when parents were not observed in the immediate vicinity of the nest (i.e., at the nest cup), although I cannot dismiss entirely the possibility that some begging events may have been in response to cues given by adults (see "Results").

A single, trained assistant watched videotapes and recorded all data pertaining to parent-absent begging events. Begging events were considered independent if they were separated by a 10 -s period during which time neither nestling begged. This period was selected to minimize the number of non-independent begging events as preliminary video analysis suggested that $10 \mathrm{~s}$ was a suitable period for nestlings to settle into a resting position after a parent-absent begging event had ended. Following previous authors (e.g., Budden and Wright 2001b; Dor et al. 2007), begging in response to parents departing from the nest was not considered to be parent-absent begging because it was initiated in the presence of parents and may have served to convey information about nestling state. For each parent-absent begging event, the apparent stimulus (or stimuli, see Table 1) that preceded each parentabsent begging event was recorded. Next, nestling begging intensity during parent-absent begging events was quantified in three ways. First, each nestling was assigned a maximum begging posture score (hereafter begging posture) following Rivers (2007), where $0=$ not begging, $1=$ gaping without neck stretched, $2=$ gaping with neck stretched to $3 / 4$ length and belly in contact with nest cup; and $3=$ gaping with neck stretched $>3 / 4$ length and belly not in contact with nest cup. Second, the time each nestling 
Table 1 Summary of the apparent stimuli that coincided with the initiation of parent-absent begging in cowbird and host nestlings

\begin{tabular}{|c|c|c|c|c|c|c|}
\hline \multirow[t]{2}{*}{ Host } & \multirow[t]{2}{*}{ Nestling } & \multicolumn{4}{|l|}{ Apparent stimulus } & \multirow[t]{2}{*}{ Total number of events } \\
\hline & & Nest movement & Nestmate behavior & Adult near nest & Unknown & \\
\hline \multirow[t]{2}{*}{ Field Sparrow } & Cowbird & $25.0 \%(13)$ & $30.8 \%(16)$ & $11.5 \%(6)$ & $32.7 \%(17)$ & 52 \\
\hline & Host & $16.7 \%(4)$ & $50.0 \%(12)$ & $12.5 \%(3)$ & $20.8 \%(5)$ & 24 \\
\hline \multirow[t]{2}{*}{ Red-winged Blackbird } & Cowbird & $16.8 \%(19)$ & $46.9 \%(53)$ & $27.4 \%(31)$ & $8.9 \%(10)$ & 113 \\
\hline & Host & $16.3 \%(15)$ & $28.3 \%(26)$ & $31.5 \%(29)$ & $23.9 \%(22)$ & 92 \\
\hline \multirow[t]{2}{*}{ Brown Thrasher } & Cowbird & $38.4 \%(56)$ & $19.9 \%(29)$ & $22.6 \%(33)$ & $19.2 \%(28)$ & 146 \\
\hline & Host & $42.4 \%(14)$ & $12.1 \%(4)$ & $27.3 \%(9)$ & $18.2 \%(6)$ & 33 \\
\hline Cowbird mean (all hosts) & & $28.3 \%(88)$ & $31.5 \%(98)$ & $22.5 \%(70)$ & $17.7 \%(55)$ & 311 \\
\hline
\end{tabular}

The percent of events due to each apparent stimulus for cowbird and host nestlings is reported within each host with the total number of events reported parenthetically. Note that cumulative percent for a nestling within a host may sum to $>100 \%$ because two apparent stimuli were attributed to a minority (i.e., $n=15$ ) of parent-absent begging events

spent begging (s) during each independent begging event was summed. Finally, the presence or absence of calling for each nestling was noted during each parent-absent begging event, although calling was an uncommon feature of the begging display of nestlings. In a minority of cases $(5.2 \%)$, parents arrived at the nest during a parent-absent begging event, at which point the parent-absent begging event was considered to be finished. Preliminary analysis found that excluding these events did not influence the way in which feeding treatments influenced the mean proportion of parent-absent events during which nestlings begged, the mean time spent begging, or the mean begging posture (J. W. Rivers, unpublished data); therefore, these events were included in all subsequent analyses.

\section{Data analysis}

Data on parent-absent begging by cowbirds was assessed in 13 sparrow nests, 17 blackbird nests, and 16 thrasher nests; some nests were represented by only one feeding treatment due to technical problems with filming. Initial analysis found that within each host, there was no difference between the two feeding treatments in the mean amount of time parents spent away from the nest during the 30 -min sessions (sparrow, $t_{37}=$ $0.37, P=0.712$; blackbird, $t_{37}=0.69, P=0.493$; thrasher, $t_{37}=$ $0.01, P=0.990)$. However, significant differences were found among hosts with regard to this metric when both feeding treatments were combined (sparrow, $11.40 \pm 1.70 \mathrm{~min}$ away from nest, $n=13$ nests; blackbird, $22.67 \pm 1.50 \mathrm{~min}$ away from nest, $n=17$ nests; thrasher, $18.88 \pm 1.51 \mathrm{~min}$ away from nest, $n=16$ nests; $\left.F_{2,43}=12.51, P<0.001\right)$. Therefore, a standardized approach was taken to assess the rate of parent-absent begging events by first summing the total number of parent-absent begging events in a nest and then dividing that value by the total time (s) parents were away from the nest. This quotient was then multiplied by 600 to adjust the rate of parent-absent begging events to $10 \mathrm{~min}$ of "parent-absent time." These new values were then averaged over all nests within each feeding treatment $\times$ host size combination using mixed effects models (see below). To calculate the proportion of parent-absent time nestlings begged, the amount of time (s) a nestling begged was summed and then that value was divided by the total amount of time (s) parents were away from the nest. As above, these values were then averaged over all nests within each feeding treatment $\times$ host size combination.

With respect to measures of begging intensity, many previous studies (e.g., Smith and Montgomerie 1991; Price et al. 1996; see Forbes 2002 for discussion) have shown that the begging behavior of nestlings within a nest are not independent, as the begging of one nestling can influence and be influenced by the begging of its nestmate(s). Therefore, instead of using raw begging metrics for assessing begging intensity, I calculated the difference between the two nestlings for a given begging metric during each parent-absent begging event (i.e., [cowbird begging metric] minus [host begging metric]). Thus, I used the differences in begging metrics between cowbird and host nestlings to model the influence of feeding treatment and host size and to maintain statistical independence. Despite the importance of analyzing the differences between cowbird and host metrics to maintain independence, raw data for cowbird and hosts are presented in some figures for ease of presentation.

Paired $t$ tests (i.e., [cowbird metric] minus [host metric]) were used to assess differences in mass between cowbird and host nestlings. To model the influence of feeding treatment and host size on the response variables, I used the PROC MIXED modeling function in SAS version 9.1 with individual nests nested within host size as a random effect, and feeding treatment (two levels: deprivation, supplementation) and host size (three levels: small, similar-sized, large) as fixed effects. When main effects (i.e., feeding treatment, host size) were significant, least square means 
(LSMEANS) analysis was used to calculate means for statistical tests because of unbalanced data, and Fisher's least significant difference tests were used for follow-up tests. Least square means and standard errors are reported unless otherwise noted, and test statistics were considered significant at $P<0.05$.

\section{Results}

Relative to the host nestlings with which they were paired, cowbirds $(10.8 \pm 0.64 \mathrm{~g})$ had significantly greater mass than sparrows $\left(5.6 \pm 0.23 \mathrm{~g}, t_{24}=7.63, P<0.001\right)$, similar mass as blackbirds (cowbird mass, $13.0 \pm 0.67 \mathrm{~g}$; blackbird mass, $\left.11.8 \pm 0.59 \mathrm{~g} ; t_{32}=1.36, P=0.184\right)$, and significantly less than thrashers (cowbird mass, $13.8 \pm 0.66 \mathrm{~g}$; thrasher mass, $\left.24.0 \pm 1.00 \mathrm{~g} ; t_{30}=-8.52, P<0.001\right)$. Cowbirds that competed against blackbird and thrasher nestlings were typically 1 day older than cowbirds that competed against sparrow nestlings, which led to differences in cowbird mass among hosts.

\section{General aspects of parent-absent begging}

Parent-absent begging occurred in response to discrete events, the majority of which (i.e., $79 \%, n=352$ ) could be assigned to one of three distinct categories of apparent stimuli: (1) movement of nest and/or nest substrate, (2) behavior of nestmate, or (3) behavior of adult(s) near nest but away from immediate vicinity of the nest cup (Table 1). On a minority of occasions, the apparent stimulus could not be assigned and was recorded as unknown. A total of 29 of the $86(34 \%)$ feeding treatment $\times$ host size combinations that were examined lacked parent-absent begging, with significantly more occurring during supplementation treatments than during deprivation treatments (24 of 29; Fisher's exact test, $\left.X^{2}=21.51, d f=1 P<0.001\right)$. Thus, feeding treatment $\left(F_{1,37}=\right.$ 23.34, $P<0.001)$ but not host size $\left(F_{2,43}=0.56, P=0.578\right)$ significantly influenced the mean number of begging events per 10 min of parental absence, with no significant feeding treatment $\times$ host size interaction $\left(F_{2,37}=0.94, P=0.399\right)$.

Influence of feeding treatment and host size on the frequency and intensity of parent-absent begging

Feeding treatment did not significantly influence the mean proportion of events during which nestlings begged $\left(F_{1,15}=2.69, P=0.122\right)$, whereas host size did $\left(F_{2,36}=6.61, P=0.004\right)$, with no significant feeding treatment $\times$ host size interaction $\left(F_{2,15}=1.07, P=0.369\right)$. Follow-up comparisons revealed that nestlings in sparrow and thrasher nests did not differ in the mean proportion of events during which they begged $\left(t_{36}=0.06, P=0.949\right)$, whereas significant differences were found between nestlings in sparrow and blackbird nests $\left(t_{36}=2.42, P=\right.$ $0.021)$ and between nestlings in thrasher and blackbird nests $\left(t_{36}=-3.33, P=0.002\right.$, Fig. 1). Cowbird nestlings begged during a significantly higher proportion of parentabsent begging events than host nestlings during both feeding treatments in both sparrow nests (deprivation, $t_{15}=2.13, P=$ 0.050; supplementation, $t_{15}=2.55, P=0.022$ ) and thrasher nests (deprivation, $t_{15}=4.30, P<0.001$; supplementation, $t_{15}=$ 3.32, $P=0.005$ ), but not blackbird nests (deprivation, $t_{15}=$ $-0.42, P=0.683$; supplementation, $t_{15}=1.35, P=0.197$ ).

With respect to the proportion of parent-absent time that nestlings begged, feeding treatment had a significant effect $\left(F_{1,37}=4.34, P=0.044\right)$, whereas host size did not $\left(F_{2,43}=\right.$ $0.35, P=0.708)$, with no significant feeding treatment $\times$ host size interaction $\left(F_{2,37}=1.02, P=0.370\right)$. Follow-up comparisons found that the mean proportion of time that nestlings begged during parent-absent periods was significantly greater during deprivation treatments in nests of the thrasher $\left(t_{37}=2.45, P=0.019\right)$ but not the sparrow $\left(t_{37}=\right.$ $0.38, P=0.704)$ or the blackbird $\left(t_{37}=0.90, P=0.374\right.$, Fig. 2). However, the significant result was due to a single outlier thrasher nest; when it was removed, there was no longer a significant difference $\left(t_{36}=1.83, P=0.075\right)$. Of note, cowbird nestlings spent more of the parent-absent period begging than their host nestmates in five of the six treatment combinations; when the thrasher outlier nest was removed, cowbird nestlings spent more time begging than host nestmates in all treatment combinations. However, none of the comparisons between cowbird and host nestlings were significant for this metric (sparrow deprivation, $t_{37}=0.81, P=0.423$; sparrow supplementation, $t_{37}=0.30$, $P=0.764$; blackbird deprivation: $t_{37}=1.61, P=0.115$; blackbird supplementation, $t_{37}=0.45, P=0.653$; thrasher deprivation: $t_{37}=1.75, P=0.089$; thrasher supplementation, $t_{37}=$ $-1.48, P=0.147)$.

Host size $\left(F_{2,36}=5.57, P=0.008\right)$ but not feeding treatment $\left(F_{1,15}=3.08, P=0.100\right)$ had a significant effect on the begging posture of nestlings, with no significant feeding treatment $\times$ host size interaction $\left(F_{2,15}=0.78, P=0.478\right)$. Follow-up comparisons found significant differences in begging posture between sparrow and blackbird nests $\left(t_{36}=\right.$ 2.05, $P=0.048)$ and thrasher and blackbird nests $\left(t_{36}=-3.15\right.$, $P=0.003)$ but not between sparrow and thrasher nests $\left(t_{36}=\right.$ $-0.17, P=0.868)$. Cowbird nestling begging posture was significantly greater than host nestmates in sparrow $\left(t_{36}=\right.$ $2.45, P=0.019)$ and thrasher nests $\left(t_{36}=4.44, P<0.001\right)$, but not blackbird nests $\left(t_{36}=0.24, P=0.808\right.$; Fig. 3a). In contrast, neither host size $\left(F_{2,36}=0.35, P=0.710\right)$ nor feeding treatment $\left(F_{1,15}=0.04, P=0.841\right)$ had a significant effect on the mean time spent begging by nestlings, with no significant feeding treatment $\times$ host size interaction $\left(F_{2,15}=0.60, P=\right.$ $0.560)$. The mean time cowbird nestlings spent begging per 

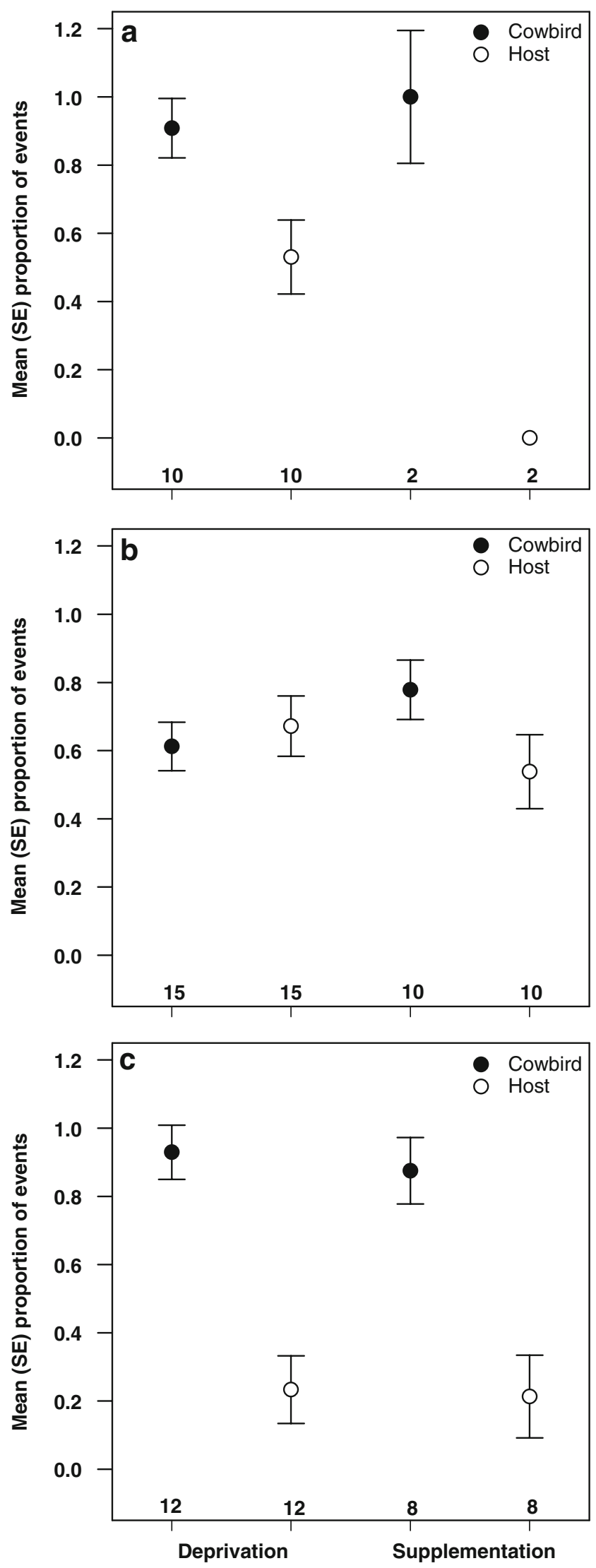

Fig. 1 Mean (SE) proportion of parent-absent begging events during which cowbird (solid circles) and host nestlings (open circles) during deprivation and supplementation treatments in nests of the a Field Sparrow, b Red-winged Blackbird, and c Brown Thrasher. Sample sizes are noted below point estimates

parent-absent begging event was not significantly different in sparrow $\left(t_{36}=0.91, P=0.369\right)$, blackbird $\left(t_{36}=1.68, P=\right.$ $0.102)$, or thrasher nests $\left(t_{36}=0.44, P=0.662\right.$, Fig. $\left.3 b\right)$. Finally, host size $\left(F_{2,36}=6.82, P=0.003\right)$ but not feeding treatment $\left(F_{1,15}=0.31, P=0.584\right)$ had a significant influence on the percent of nests during which nestlings called, with a significant feeding treatment $\times$ host size interaction $\left(F_{2,15}=\right.$ 4.22, $P=0.035)$ due to the high rate of calling by cowbird nestlings in thrasher nests relative to cowbird nestlings in sparrow and blackbird nests. Follow-up comparisons found no difference in calling by nestlings between sparrow and blackbird nests $\left(t_{36}=0.54, P=0.596\right)$ but significant differences between sparrows and thrashers $\left(t_{36}=-2.12, P=0.041\right)$ and blackbirds and thrashers $\left(t_{36}=-3.62, P<0.001\right)$. Cowbird nestlings called significantly more often than host nestlings during parent-absent begging events when competing against thrasher nestlings $\left(t_{36}=4.97, P<0.001\right)$ but neither sparrow nestlings $\left(t_{36}=0.68, P=0.499\right)$ nor blackbird nestlings $\left(t_{36}=\right.$ $0.11, P=0.912$, Fig. 3c).

\section{Discussion}

The influence of short-term need and host size on the frequency of parent-absent begging

As predicted, feeding treatments had a strong influence on the frequency of parent-absent begging behavior, with deprivation treatments increasing the rate of parent-absent begging and the proportion of time that nestlings spent begging in the absence of parents. Because the period of parent-absent time within each host was similar during both feeding treatments, this indicates that the time nestlings spent begging during deprivation treatments was greater than during supplementation treatments. In contrast, the proportion of total events during which nestlings begged was not strongly influenced by feeding treatment and instead varied among hosts. This pattern was generally similar for cowbird and host nestlings for both metrics, although cowbirds typically begged during a greater proportion of events, and the magnitude of the difference between deprivation and supplementation treatments in cowbirds was more pronounced than host nestlings. That nestlings increased their total time spent begging during food-deprived periods is not surprising and complements a growing body of evidence that has found nestling songbirds increase the extent of parent-absent begging as the interval 

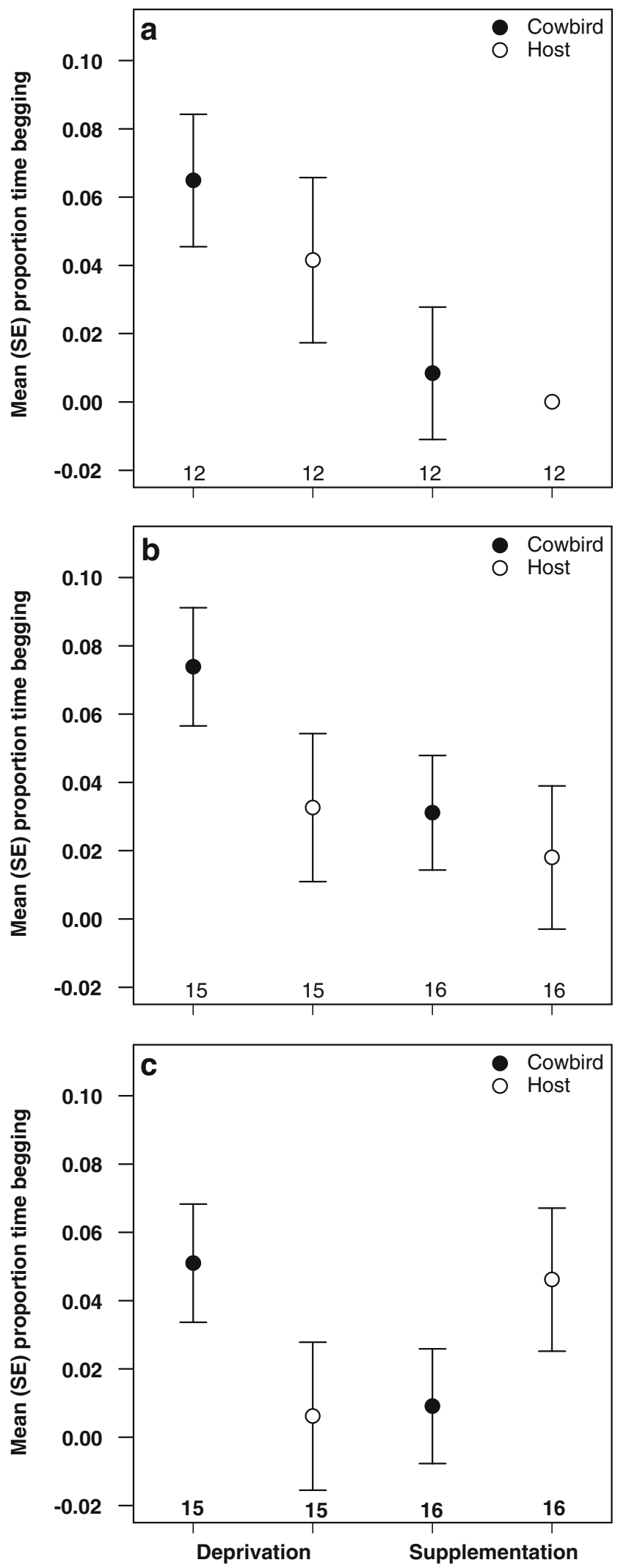

Fig. 2 Mean (SE) proportion of time spent begging during parentabsent periods for cowbird (solid circles) and host nestlings (open circles) during deprivation and supplementation treatments in nests of the a Field Sparrow, b Red-winged Blackbird, and c Brown Thrasher. Sample sizes are noted below point estimates

between feeding visits increases (Leonard and Horn 2001; Dor et al. 2007) or when nestlings are experimentally deprived of food (Price and Ydenberg 1995; Maurer et al. 2003; Leonard et al. 2005; Dickens and Hartley 2007; Bulmer et al. 2008). Nevertheless, previous investigations that manipulated hunger did not quantify how time budgets of parent-absent begging changed between deprivation and supplementation treatments as in this study, so it is unknown the extent to which data from this study are relevant to other altricial species (but see Roulin 2001). With respect to cowbirds and hosts, the pattern of more time spent begging during food deprivation periods mirrors an increase in total time spent begging by nestlings during provisioning events in the first $30 \mathrm{~min}$ (J. W. Rivers, unpublished data), indicating that begging during both feeding events and parental absences increase similarly when nestlings are deprived of food. The extent to which these increases in begging may be costly to nestlings is unclear, but the 2.4-7.7x increase in time spent begging by cowbirds could potentially increase begging costs (Chappell and Bachman 2002). Because they consistently spend more time begging than hosts and they often have prolonged begging bouts during feeding visits and during parent-absent periods (Redondo 1993; Davies et al. 1998; Lichtenstein and Dearborn 2004; Tanaka and Ueda 2005; Rivers 2007; this study), future investigations of the physiological costs of begging would do well to examine this topic in brood parasites.

Among hosts, cowbirds participated in a smaller proportion of parent-absent begging events in blackbird nests relative to sparrows and thrashers, a finding that may be explained by the different competitive environments these three hosts offer. When the same individuals were examined in a companion study, cowbirds that competed against blackbird nestmates received a "mean payoff" (measured as the average volume of food gained per second spent begging) that was several times greater than either the sparrow or thrasher (Rivers 2007). Taken together with the results of this study, this suggests that cowbirds in blackbird nests may have participated in a lower proportion of parentabsent begging events because they may have been more satiated than cowbirds in sparrow or thrasher nests. An alternative explanation for this pattern is that because the total number of parent-absent begging events was greater in blackbirds, cowbirds may have reduced the number of times they begged to incorrect stimuli through habituation. Thus, it appears that a higher payoff during begging, habituation to incorrect stimuli, or both may have been 

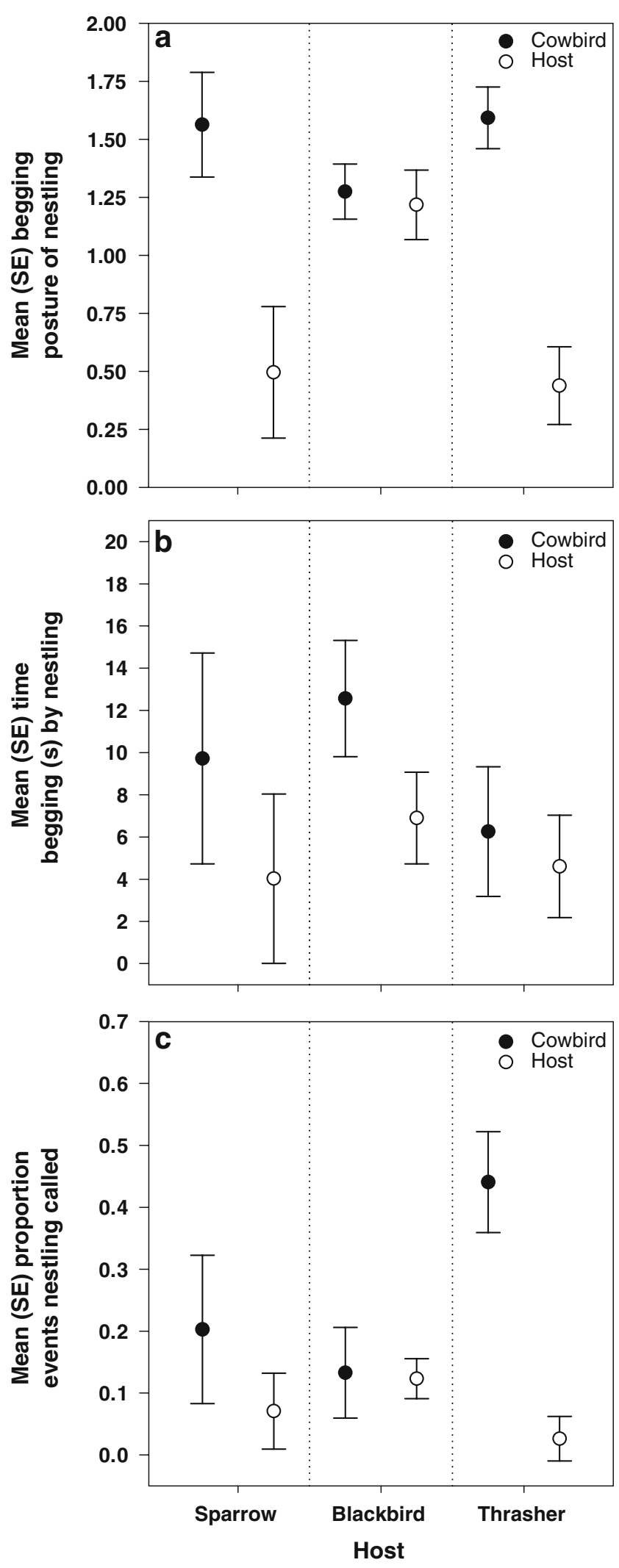

Fig. 3 a Mean (SE) begging posture and b mean (SE) time spent begging during parent-absent begging events, and $\mathbf{c}$ mean (SE) percent of events during which cowbirds (solid circles) and host nestlings (open circles) called in nests of the Field Sparrow ( $n=10$ nests), Redwinged Blackbird ( $n=16$ nests), and Brown Thrasher ( $n=13$ nests)

responsible for cowbirds participating in a lower proportion of parent-absent begging events in blackbird nests relative to sparrows and thrashers.

The influence of short-term need and host size on the intensity of parent-absent begging

Unlike the frequency of parent-absent begging and the total proportion of time spent begging during such events, feeding treatments did not influence three aspects of begging intensity: mean begging posture, mean time spent begging, or the proportion of events during which nestlings called. Instead, it was differences among hosts that led to differences in the intensity of begging during parent-absent periods for nestlings. With respect to begging posture, cowbird nestlings had significantly higher begging posture scores than their sparrow and thrasher nestmates but not relative to blackbird nestmates, a pattern also found during feeding visits that took place in the same 30-min period (J. W. Rivers, unpublished data). In contrast, the average time spent begging by cowbirds during parent-absent begging events did not vary among hosts as it did during feeding visits, with cowbirds spending the least amount of time begging in blackbird nests relative to the other two hosts (J. W. Rivers, unpublished data). One plausible explanation for this pattern is that cowbird nestlings appear to initiate begging in response to nestmate behavior and may use a general rule where they typically beg longer than their nestmate(s) (see Glassey and Forbes 2003). Nevertheless, it may be possible that some other unknown factors influenced the average time spent begging by cowbird nestlings and led to the differences observed between provisioning events and parent-absent periods.

With respect to calling behavior, the significant interaction between host and treatment appears to be driven by a marked increase in calling by cowbirds, but not host nestlings, during deprivation treatments in thrasher nests. Why cowbirds called more often in thrasher nests is not clear, but it may pertain to the finding that cowbirds fared poorly in thrasher nests during trials and received only a small portion of the food that thrasher parents brought to the nest (Rivers 2007). In the strong competitive environment of the thrasher, cowbirds may have responded by increasing their calling rate relative to nests where they faced a weaker competitive environment. However, little is known about the relative components of the cowbird begging signal and how it influences parent provisioning, so this idea remains speculative at this point. 
The frequency vs. intensity of begging and its implications for the evolution of begging displays in brood parasites

This study revealed different influences of short-term need and host size on cowbird begging. On one hand, feeding treatments led to an overall increase in the number of begging events and the total time spent begging by cowbird nestlings in the absence of parents, and this pattern was similar among hosts. On the other hand, feeding treatments influenced neither the proportion of events during which cowbird nestlings called nor three measures of begging intensity during parent-absent begging events; instead, these variables varied relative to host size. In cowbirds, therefore, the frequency of begging was only influenced by short-term need, whereas begging intensity during parentabsent events was only influenced by the host against which cowbirds competed. Although no other study has examined parent-absent begging in a brood parasitic species under natural conditions, these results run counter to most studies of begging during provisioning events by brood parasites. Those studies have found that begging intensity during feeding events (e.g., time spent begging, begging posture) varied relative to hunger level (Butchart et al. 2003; Hauber and Ramsey 2003; Lichtenstein and Dearborn 2004; Tanaka and Ueda 2005; but see Redondo 1993). Nevertheless, the results from the current study mirror begging during feeding visits from the same sample of nests (Rivers 2007) and match the general pattern that the begging intensity of cowbirds during parent-absent events was consistently higher than that of hosts of all sizes in this study in accordance with previous examinations of cowbird begging during feeding visits (Briskie et al. 1994; Lichtenstein and Sealy 1998; Dearborn 1998; Glassey and Forbes 2003; Rivers 2007).

Given that disparate feeding treatments did not lead to significant differences in begging intensity by cowbird during parent-absent events, it is worth considering the implications of this finding on the evolution of begging displays in brood parasites. In these species, begging intensity is typically quantified according to the manner in which begging occurs during a given begging event (e.g., begging posture, call rate) with the assumption that more intense begging displays (e.g., greater begging posture, increased call rate) lead to higher fitness costs (see Chappell and Bachman 2002; Haskell 2002). In contrast, the frequency of begging events has not typically been considered an index of begging intensity, in part because the frequency of begging during provisioning events is constrained by the feeding rates of parents. If, however, we expand the definition of begging intensity to include the frequency of begging during both feeding visits and parentabsent periods, then feeding treatment would be considered to have a strong influence on cowbird begging intensity in this study, as cowbirds begged more frequently and for longer periods of time when food-deprived relative to when food-supplemented. Such an approach seems reasonable, although it should be noted that the mixed results for begging costs make it unclear the extent to which begging is costly to nestlings (Chappell and Bachman 2002; Haskell 2002). Nevertheless, the frequency of begging appears to be an important factor that may further distinguish the begging behavior of brood parasitic species from those of nonparasitic species. Moreover, it suggests that both begging intensity during begging events and the frequency of such events should be examined together in future studies assessing factors influencing the evolution of begging displays in brood parasites and non-parasitic species alike.

Acknowledgements This research was supported by funding from the Chapman Memorial Fund of the American Museum of Natural History, the American Ornithologists' Union, the Cooper Ornithological Society, Helmetcamera.com, the Los Angeles Audubon Society, Sigma Xi, and the NSF Long Term Ecological Research program at Konza Prairie Biological Station. I thank Kara Mathews for watching videotapes; Erin McCarthy, Jarrod Bowers, Karl Kosciuch, Drew Miller, Ryan Rehmeier, and Brett Sandercock for assistance with locating nests; Brett Sandercock for extensive logistical support for this research; Tom Loughin, Steve Gaines, and Bill Rice for statistical advice; Roi Dor, Mike Kuehn, Jim Reichman, Steve Rothstein, Manuel Soler, Bob Warner, and two anonymous reviewers for helpful comments on previous drafts of the manuscript; and Jim Briskie, Marty Leonard, Gabriela Lichtenstein and various members of the Rothstein Gang for insightful discussions. The experiments described in this study were conducted under state, federal, and institutional permits as well and comply with the guidelines for the ethical treatment of animals as outlined by ABS/ASAB.

Open Access This article is distributed under the terms of the Creative Commons Attribution Noncommercial License which permits any noncommercial use, distribution, and reproduction in any medium, provided the original author(s) and source are credited.

\section{References}

Briskie JV, Sealy SG (1990) Evolution of short incubation periods in the parasitic cowbirds, Molothrus spp. Auk 107:789-194

Briskie JV, Naugler CT, Leech SM (1994) Begging intensity of nestling birds varies with sibling relatedness. Proc R Soc Lond B 258:73-78

Budden AE, Wright J (2001a) Begging in nestling birds. Curr Ornithol 16:83-118

Budden AE, Wright $J$ (2001b) Falling on deaf ears: the adaptive significance of begging in the absence of a parent. Behav Ecol Sociobiol 49:474-481

Bulmer E, Celis P, Gil D (2008) Parent-absent begging: evidence for sibling honesty and cooperation in the spotless starling (Sturnus unicolor). Behav Ecol 19:279-284

Butchart SHM, Kilner RM, Fuisz T, Davies NB (2003) Differences in the nestling begging calls of hosts and host-races of the common cuckoo, Cuculus canorus. Anim Behav 65:345-354 
Chappell MA, Bachman GC (2002) Energetic costs of begging behavior. In: Wright JJ, Leonard ML (eds) The evolution of begging: competition, cooperation and communication. Kluwer, The Netherlands, pp 143-162

Clemmons JR (1995) Vocalizations and other stimuli that elicit gaping in nestling black-capped chickadees (Parus atricapillus). Auk 112:603-612

Davies NB (2000) Cuckoos, cowbirds, and other cheats. Princeton University Press, Princeton

Davies NB, Kilner RM, Noble DG (1998) Nestling cuckoos, Cuculus canorus, exploit hosts with begging calls that mimic a brood. Proc R Soc Lond B 265:673-678

Dearborn DC (1998) Begging behavior and food acquisition by brown-headed cowbird nestlings. Behav Ecol Sociobiol 43:259270

Dickens M, Hartley IR (2007) Stimuli for nestling begging in blue tits Cyanistes caeruleus: hungry nestlings are less discriminating. J Avian Biol 38:421-426

Dor R, Kedar H, Winkler DW, Lotem A (2007) Begging in the absence of parents: a "quick on the trigger" strategy to minimize costly misses. Behav Ecol 18:97-102

Elliot PF (1978) Cowbird parasitism in the Kansas tallgrass prairie. Auk 95:161-167

Forbes S (2002) Statistical challenges in the study of nestling begging. In: Wright JJ, Leonard ML (eds) The evolution of begging: competition, cooperation and communication. Kluwer, The Netherlands, pp 473-491

Forbes S, Glassey B (2000) Asymmetric sibling rivalry and nestling growth in red-winged blackbirds (Agelaius phoeniceus). Behav Ecol Sociobiol 48:413-417

Friedmann H, Kiff LF (1985) The parasitic cowbirds and their hosts. Proc West Found Vert Zool 2:227-302

Glassey B, Forbes S (2003) Why brown-headed cowbirds do not influence red-winged blackbird parent behavior. Anim Behav 65:1235-1246

Harper AB (1986) The evolution of begging: sibling competition and parent-offspring conflict. Am Nat 128:99-114

Haskell DG (2002) Begging behavior and nest predation. In: Wright JJ, Leonard ML (eds) The evolution of begging: competition, cooperation and communication. Kluwer, The Netherlands, pp 163-172

Hauber ME (2003) Lower begging responsiveness of host versus parasitic brown-headed cowbird (Molothrus ater) nestlings is related to species identify but not to early social experience. J Comp Pyschol 117:24-30

Hauber ME, Ramsey CK (2003) Honesty in host-parasite communication signals: the case for begging by fledgling brown-headed cowbirds, Molothrus ater. J Avian Biol 34:339-344

Holen OH, Saetre GPP, Slagsvold T, Stenseth NC (2001) Parasites and supernormal manipulation. Proc R Soc Lond B 268:2551-2558

Jensen WE, Cully JF (2005) Geographic variation in brown-headed cowbird (Molothrus ater) parasitism on dickcissels (Spiza americana) in Great Plains tallgrass prairie. Auk 122:548-660

Khayutin SN (1985) Sensory factors in the behavioral ontogeny of altricial birds. Adv Stud Behav 5:105-152

Kilner RM, Johnstone RA (1997) Begging the question: are offspring solicitation behaviors signals of need? Trends Ecol Evol 12:11-15

Kilner RM, Noble DG, Davies NB (1999) Signals of need in parentoffspring communication and their exploitation by the common cuckoo. Nature 397:667-672
Kilpatrick AM (2002) Variation in growth of brown-headed cowbird (Molothrus ater) nestlings and energetic impacts on their host parents. Can J Zool 80:145-153

Leonard ML, Horn AG (2001) Begging in the absence of parents by nestling tree swallows. Behav Ecol 12:501-505

Leonard ML, Horn AG, Mukhida A (2005) False alarms and begging in nestling birds. Anim Behav 69:701-708

Lichtenstein G (2001) Selfish begging by screaming cowbirds, a mimetic brood parasite of the bay-winged cowbird. Anim Behav 61:1151-1158

Lichtenstein G, Dearborn DC (2004) Begging and short-term need in cowbird nestlings: how different are brood parasites? Behav Ecol Sociobiol 54:188-193

Lichtenstein G, Sealy SG (1998) Nestling competition, rather than supernormal stimulus, explains the success of parasitic brownheaded cowbird chicks in yellow warbler nests. Proc R Soc Lond B 265:249-254

Lowther P (1993) Brown-headed cowbird (Molothrus ater). In: Poole A, Gill F (eds) The birds of North America. The Academy of Natural Sciences and The American Ornithologists' Union, Philadelphia

Maurer G, Magrath RD, Leonard ML, Horn AG, Donnelly C (2003) Begging to differ: scrubwren nestlings beg to alarm calls and vocalize when parents are absent. Anim Behav 65:1045-1055

Motro U (1989) Should a parasite expose itself? (Some theoretical aspects of begging and vigilance behavior). J Theo Biol 140:279-287

Parker TH (1999) Responses of Bell's vireos to brood parasitism by the brown-headed cowbird in Kansas. Wilson Bull 111:499-504

Price K, Ydenberg R (1995) Begging and provisioning in broods of asynchronously-hatched yellow-headed blackbird nestlings. Behav Ecol Sociobiol 37:201-208

Price K, Harvey H, Ydenberg R (1996) Begging tactics of nestling yellow-headed blackbirds, Xanthocephalus xanthocephalus, in relation to need. Anim Behav 51:421-435

Redondo T (1993) Exploitation of host mechanisms for parental care by avian brood parasites. Etologia 3:235-297

Rivers JW (2007) Nest mate size, but not short-term need, influences begging behavior of a generalist brood parasite. Behav Ecol $18: 222-230$

Rothstein SI (1975) An experimental and teleonomic investigation of avian brood parasitism. Condor 77:250-271

Rothstein SI (1990) A model system for coevolution: avian brood parasitism. Ann Rev Ecol Syst 21:481-508

Roulin A (2001) Food supply differentially affects sibling negotiation and competition in the barn owl (Tyto alba). Behav Ecol Sociobiol 49:514-519

Roulin A (2002) The sibling negotiation hypothesis. In: Wright JJ, Leonard ML (eds) The evolution of begging: competition, cooperation and communication. Kluwer, The Netherlands, pp 107-126

Roulin A, Kolliker M, Richner H (2000) Barn owl (Tyto alba) nestlings vocally negotiate resources. Proc R Soc Lond B 267:459-463

Smith HG, Montgomerie R (1991) Nestling American robins compete with siblings by begging. Behav Ecol Sociobiol 29:307-312

Starck JM, Ricklefs RE (1998) Avian growth and development. Oxford University Press, Oxford

Tanaka KD, Ueda K (2005) Horsfield's hawk-cuckoo nestlings simulate multiple gapes for begging. Science 308:653

Teather KL (1992) An experimental study of competition for food between male and female nestlings of the red-winged blackbird. Behav Ecol Sociobiol 31:81-87 